\title{
Differences in Individualistic and Collectivistic \\ Tendencies among College Students in Japan \\ and the United States
}

Emiko Kobayashi

Kanazawa University, Japan

Harold R. Kerbo

California Polytechnic State University, USA

Susan F. Sharp

University of Oklahoma, USA

\begin{abstract}
It is a worldwide stereotype that Japanese, compared to Americans, are oriented more toward collectivism. But this stereotypical notion of more collectivism among Japanese, which typically stems from a view that individualism and collectivism stand at opposite ends of a continuum, has been filled with dashed empirical findings, especially in a sample of college students. In the current study, following the view that individualism and collectivism are two separate concepts rather than one with two extremes, we test and compare both individualistic and collectivistic tendencies among college students in Japan and the United States. A review of theories and research on this dimension of cultural variability across the two diverse cultures and the literature on societal pressure of collectivity and on parents as primary socialization agents of culturally expected values lead to two hypotheses: 1) Japanese college students tend less toward individualism than do Americans, and 2) Japanese college students tend less toward collectivism than do Americans. Analysis of identical survey data from college students in Japan and in the United States provides strong support for both hypotheses.
\end{abstract}

Despite modernization, the old images of Japan held by Westerners, and even among Japanese themselves, persist. One of the most important of these images is that Japanese people are more collectivistic than Westerners, and especially more so than Americans - a stereotype 
based primarily on an abundance of qualitative studies on stronger 'group-orientation' among Japanese than among Americans (e.g. Eisenstadt, 1996; Jansen, 2000; McClain, 2002; Parsons, 1951; Reischauer, 1970; Rosenstone, 1988) and some empirical evidence on lower individualism in Japan than in the United States (e.g. Hofstede, 1980; Hofstede and Bond, 1984; Hofstede and Hofstede, 2004).

Despite this research and the long-running assumption that the Japanese must be understood with reference to this value orientation of individualism versus collectivism, we argue that this stereotype should be seriously challenged. We question this stereotype in large part because this orientation at the individual level may be different from, although not always incompatible with, that at the cultural level (e.g. Matsumoto and Juang, 2004) and because this stereotype is based on a view that individualism and collectivism are simply opposite ends of the same value dimension (e.g. Freeman, 1997; Kagitcibasi, 1987, 1994).

During the past 30 years, in cross-cultural psychology and intercultural communication, much effort has been devoted to ascertaining the validity of this stereotype (for a meta analysis, see Takano and Osaka, 1999; see also Matsumoto and Juang, 2004). Normally culture, as a system of knowledge, is believed to influence and guide our behavior by providing us with 'interpretations of social life, role expectations, common definitions of situations, and social norms' (Olsen, 1978: 107; see also Keesing, 1974). Questioning the equation of the most favorably received cultural-level scores reported by Hofstede (1980) with individual orientation toward individualism-collectivism $(I-C)$, however, researchers have attempted to find ways to study this value dimension at the individual level. Different researchers have used different methodologies. But the majority have concentrated on survey data because they provide the greatest opportunity to test a wide variety of items from refinements of Hofstede’s (1980) 
seminal individualism index. Yet, there is no consistency in stronger collectivism among Japanese compared to Americans. Especially, when a sample of college students is drawn from the two countries, the respondents do not seem to represent the predominant cultural $I-C$ tendency (for a concise summary, see Matsumoto, 2002).

In nearly all the survey research, the focus has been simply on the differences in individualistic and collectivistic tendencies between Japanese and Americans. Thus, little has been understood regarding why these differences appear. We contend, however, the explicit emphases on societal pressure of collectivity and on early childhood socialization, through which children are reinforced by their parents for the culturally expected values, provide a perspective for understanding such differences. Beccaria (1963 [1764]) and Bentham (1948 [1780]) indicated centuries ago that people are rational beings who exercise free will in making decisions as to what they will do. As a result, the greater pressure for collectivity and conformative behavior in Japanese society is expected to drive its people into a stronger aversion to collectivism.

Additionally, Matsumoto (2002) noted recently, but offered no evidence, that the parental role as a moral beacon has been descending rapidly in Japan, and it is possible that Japanese children of today may be deprived of the opportunity to learn not only an individualistic cultural theme but also a collectivistic cultural theme. Therefore, the combination of these two factors, as applied to the individual $I-C$, seem to suggest that Japanese youth might be not only less individualistic but also less collectivistic than are Americans, with differences of this still being observed among young adults and university students. ${ }^{1}$

\section{AN OVERVIEW OF INDIVIDUALISM AND COLLECTIVISM IN JAPAN AND THE UNITED STATES}


Our expectations concerning the differences in individualistic and collectivistic tendencies of college students in Japan and the United States are grounded primarily in 1) Hofstede’s (1980) findings on individualistic and collectivistic cultures, 2) the notion of people exercising free will in making choices as to what they will do, and 3) previous ideas and research on differences in early childhood socialization across the two cultures, as they pertain to parental role as moral beacons.

The idea that Japan, in contrast to the United States, is more collectivistic has a long history. By the late 1800s shortly after the opening of Japan in 1854, some Western social scientists such as Percival Lowell (1888) were already putting forth the themes of Japan’s ‘lack of individuality’, ‘collectivist orientation’ and other supposed characteristics which make the Japanese almost polar opposites of Western civilization (Rosenstone, 1988). The most widely known statement on this topic no doubt is Ruth Benedict's (1946) The Chrysanthemum and the Sword (see also Abegglen, 1958). The idea that Japan tends more toward collectivism, while the US tends more toward individualism also gained popularity among Japanese scholars (e.g. Doi, 1971, 1985; Kawasaki, 1969; Nakane, 1970). 'Individualism', in this context, means placing an emphasis on individual identity over group identity, individual needs and rights over group obligations, and individual pleasure over adherence to group norms (for a discussion of individualism in the United States, see Bellah et al., 1985). 'Collectivism', on the other hand, grants priority to group identity over individual identity, shared in-group beliefs over unique individual beliefs, and cooperation with in-group members over maximizing individual outcomes (see Gudykunst et al., 1996).

In the 1980s, researchers, especially Geert Hofstede (1980; Hofstede and Bond, 1984; see also Hampden-Turner and Trompenaars, 1993) in the field of crosscultural psychology began 
developing measures of $I-C$ and using these measures to collect data from diverse cultures (see also Triandis, 1988, 1990, 1995). In his seminal empirical study of IBM workers around the world, Hofstede (1980; see also Hofstede and Hofstede, 2004) reported that the United States scored 91 (ranked the first out of 39 countries) on his individualism index (51 is the average score), while Japan received a lower score of 46 (ranked the 22nd). Therefore, as the Japanese economy came to challenge American economic dominance by the 1980s, one key to differing management styles between Western and Japanese corporations could be found with the more collectivistic orientation of Japanese employees (for example, see Lincoln and Kalleberg, 1985, 1990; Lincoln et al., 1995).

Since Hofstede’s original formulation and research, others have modified his basic idea. Hofstede's scale items were unique to the workplace. And his research, due to a view that $I$ - $C$ is a bipolar continuum, offers no empirical evidence that Japan is indeed more collectivistic than the US. In the early 1990s, two measures were developed in the United States, and they have now dominated the study of $I-C$ across cultures. They are the individual-level equivalent of the cultural variability dimension of $I-C$ and refer to the degree to which people conceive of themselves as separate from or connected to others. In the tradition of theory and research on 'value orientations’ (e.g. Rokeach, 1973), Schwartz (1990, 1992; Schwartz and Bilsky, 1987, 1990) designed more global measures of $I-C$ as general value orientations. Markus and Kitayama (1991; see also DeGooyer, 1992) linked the idea to the self-concept literature, distinguishing between and measuring an 'independent self-construal' (i.e. individualism) versus an 'interdependent self-construal' (i.e. collectivism). In their research, Gudykunst et al. (1996) included questionnaire items from refinements of Schwartz's and Markus and Kitayama’s scales and found that Japanese, compared to Americans, scored lower on 'individualistic value 
orientation' and 'independent self-construal', while they scored higher on 'collectivistic value orientation' and 'interdependent self-construal'.

While research on individualism tends to yield theoretically predicted outcomes, the dustbin of collectivism has been filled with dashed empirical expectations. A recent review of the literature led Matsumoto and Juang (2004; see also Takano and Osaka, 1999) to conclude that the data collected by Hofstede (1980) support the theory that Japanese are more collectivistic than are Americans, but the findings thereafter, especially those from a sample of college students, tend to be less supportive. More recently, Matsumoto (2002: 53, italics added) concluded that, 'the stereotype of [Japanese being more collectivistic than Americans] is simply not congruent with contemporary Japanese culture and the psychology of the younger generations'. For example, Matsumoto et al. (1997) uncover evidence for less collectivistic values among Japanese college students than among Americans. Kim et al. (1996) also find that Japanese college students have less interdependent and independent self-construals than do Americans. The test has added importance because, by examining both individualistic and collectivistic tendencies of Japanese and Americans, Kim et al., pointed out the possibility that Japanese young adults (i.e. college students) are not only less individualistic but also less collectivistic than are Americans. If this speculation is correct, according to Kim et al., the Japanese college students are then labeled as 'marginal', as opposed to the Americans as 'bicultural'.

Currently, studies on I-C in Japan and the United States seem headed toward a common fate: new measures will be continuously developed and will be applied to narrowly defined research questions about differences in $I-C$ in the two cultures, before a theoretically sound explanation(s) of the contradictory findings is ever presented. 
We argue that expanding the research on $I-C$ to encompass societal pressure of collectivity and contemporary parental practices permits a better understanding of the psychology of younger generations of today beyond the traditional notion of Japanese collectivism. Beccaria (1963 [1764]) and Bentham (1948 [1780]) noted centuries ago that people are self-serving and rational beings who exercise free will in making choices. As a result, if forced to conform, they tend to resist the external power. The theme of rebellion against the society, parents, and others can be found throughout Japanese literature. Because the pressure on Japanese people to conform is great, the characters of Soseki Natsume's novels such as 'Sore Kara' ('And Then ...') ‘K jin' ('The Wayfarer’) and 'Mon' ('The Gate') and those of others’ strike a desired emotion to rebel. Consequently, the greater societal pressure to collectivity and conformative behavior in the Japanese society should result in a smaller difference in collectivistic tendency between Japanese and Americans.

Moreover, we argue that the deteriorating role of Japanese parents as those who are the primary agents to instill the collectivistic values and the interdependent self-construal into their offspring contributes, at least to some extent, to a smaller difference in collectivism between Japanese and American youth. Recently, Matsumoto (2002) concurs with this argument as he presents renewed opposition to the notion of Japanese being more collectivistic than Americans and suggests new directions for research to consider the role of parents as primary socialization agents of culturally expected values and self-construals. In today’s Japan, Matsumoto (2002) argues, more and more Japanese mothers are willing to ignore behavioral problems as long as their children continue to study and earn good grades. Many fathers, too, are reluctant to correct their children because they prefer to have pleasant times and feelings with their children during little time they share. As a result, according to Matsumoto’s argument, the declining parental role 
as moral beacons in the Japanese family might lead to impedance of their offspring to acquire not only individualistic values and an independent self-construal, but also collectivistic values and an interdependent self-construal that should be predominant in collectivistic nature of Japanese culture.

Both Japanese and Americans have seconded that a dearth of firm discipline is a key characteristic of the current Japanese childrearing (e.g. Azuma, 1986; Bacon and Ichikawa, 1988; Hoffman, 2003). In her cross-cultural study on parenting, Machida (1996; see also Conroy et al., 1980; Lewis, 1995) finds that Japanese parents, especially mothers, are less inclined than their American counterparts to give direct instructions on how to talk, think, and behave. Power et al. (1992) also observe that Japanese mothers are more hesitant to respond to child misconduct with material and social consequences. Therefore, as the treatment of children appears to be more tolerated and lenient in terms of socialization for conscience about right and wrong, a stronger tendency for collectivism among Japanese youth compared to Americans is expected to diminish over time.

This Japanese approach to child-rearing, in fact, plays a key role in preparing children for the opportunity structure they will confront as they transition into adulthood. Kerbo and McKinstry (1998; see also Rohlen, 1983; Sugimoto, 2003; White, 1987; Yamada, 2000) observe that in Japan, unlike the United States, opportunities for success are channeled into an extremely tapered selection process with no alternative paths or second chances. Adult outcomes are determined during a condensed period of a couple days in spring when a person 18 years of age sits for the examination for entrance into the university system. With the aim of preparing their children for this examination, along with the lapse of Confucian teachings unlike Korea and China (e.g. Sengoku, 2000, 2006), Japanese parents are more and more tolerant of and 
indifferent to inculcating proper social behavior and moral principles. For the Japanese children, this results in less likelihood to acquire the culturally expected collectivistic values and interdependent self-construal, with a latent effect of pushing them into an 'apathy' syndrome typically characterized as ‘mukiryoku’ (lethargic) and 'mukanshin' (indifference).

Additionally, we argue that self-development emphasized in highly individualistic American culture, coupled with the greater societal pressure of collectivity and the lack of discipline in the Japanese family, provides an interesting insight into a possibility that the theoretically predicted cultural dif ference might be even reversed in the direction, thereby producing stronger collectivism among American college students compared to their Japanese counterparts. At least in the United States, Guisinger and Blatt (1994; see also Kagitcibasi, 1996a, 1996b; Niedenthal and Beike, 1997) suggest, socialization is predicated on selfdevelopment, by which they mean a mature self attainable from two aspects of developments the development of a sense of independence and the development of interpersonal relatedness. These two developmental processes are not mutually exclusive. Rather, they co-vary positively, with the development of a mature self in one aspect dependent, at least to some extent, on the development of a mature self in the other. Consequently, the stronger tendency of collectivism among American youth, compared to Japanese, could result from the socialization of American children for cooperation and altruism as aspects of self-development equally as important as independence and autonomy.

\section{HYPOTHESES}

The arguments above lead to the following hypotheses: 
Hypothesis 1: Japanese college students tend to have a less individualistic value orientation and a less independent self-construal than do Americans.

Hypothesis 2: Japanese college students tend to have a less collectivistic value orientation and a less interdependent self-construal than do Americans.

\section{METHOD}

\section{Samples}

Data for this research come from a larger cross-cultural study of individualistic and collectivistic orientation in behaviors in Japan and the United States. The two identical surveys conducted simultaneously in the two countries allows for more direct comparisons of analysis and finding without confounding methodological artifacts. In April 2003, identical questionnaires, but in different languages, were administered to samples of students in a public university in Japan and a comparable one in the US.2 The US university has a total enrollment (graduate and undergraduate) of approximately 22,000 and is within the boundaries of a metropolitan area of about 1.1 million inhabitants that also contains the state's capital. The Japanese university has an enrollment of approximately 16,500 students and is located within a metropolitan area of about 2.2 million inhabitants that contains the prefecture's capital city. Thus, both the American and the Japanese universities are in large (but not the largest) metropolitan areas that include a state/prefecture capital.

The data collection instrument, a self-report survey questionnaire, was initially designed in English. Through a series of pre-tests, the questionnaire was then translated into Japanese. ${ }^{3}$ The survey was administered to both the American and the Japanese university students in the 
same month of the year (April). ${ }^{4}$ In the United States, respondents were enrolled in an Introduction to Sociology course that is taken primarily by freshman and sophomores, few of whom have yet declared a major and most of whom will not become sociology majors. In Japan, our respondents were registered in the sophomore level courses in a variety of majors, including literature, economics, science, engineering, and education. ${ }^{5}$

A total of 443 Japanese and 505 English questionnaires were distributed to the students in the Japanese and the US universities, respectively, along with a cover letter indicating that participation was voluntary and that all responses were anonymous. ${ }^{6}$ Nine non-Japanese respondents in the Japanese sample and 136 non-white respondents in the US sample were eliminated, resulting in 433 Japanese respondents and 369 white Americans. ${ }^{7}$ In the Japanese sample 71.1 percent were male, while in the US sample 43.1 percent were male. ${ }^{8}$ Other potential differences between the two samples were considered that might need to serve as control variables. The mean age of the two samples did differ slightly, but significantly, as did the percent who had lived in single-adult households. So, as described in more detail below, age and family structure are included as control variables. Although the two samples did not differ in family socio-economic status, as measured by parental education, it is included in theanalysis.

\section{Measures}

Individualistic and Collectivistic Values

One of the most commonly used measures of value orientations is the one developed by Gudykunst et al. (1996), designed to tap Schwartz’s (1992) conceptualization of values that serve individualistic and collectivistic interests. Our questionnaire included items and response options from this study of Japanese and American college students concerning value orientations. To 
measure ‘Individualistic Value-Orientation’ and ‘Collectivistic Value- Orientation’, we asked respondents to indicate, on a seven-point scale, 'how important each of the following values is as a guiding principle in your life'. Possible responses ranged from 'not important at all' (coded 1) to 'extremely important' (coded 7). The nine items we included that are identified as 'individualistic' are: a sense of accomplishment, pleasure, ambitious, capable, imaginative, independence, intellectual, logical, self-respect. The ten items that we considered to be 'collectivistic' are: helpful, obedient, polite, obedience to parents, meeting all obligations, harmony with others, cooperative with others, a sense of belonging, observing rites and social rituals, and interdependent with others.

Before creating a single scale for each of the two value orientations from the combined samples, we assessed the possibility that the dimensionality of value orientation is not the same in the two countries. In both cases, therefore, the eigenvalues indicated undimensionality, and the reliability coefficients were nearly identical for individualistic value-orientation (.79 in Japan and .84 in the United States) and collectivistic value-orientation (.87 in Japan and .90 in the United States).

These analyses suggest that we can be justified in creating a single scale for each of the value orientations from the combined samples. The results from the factor analysis of the items are reported in Table 1. Again, the eigenvalues (see note in table) clearly indicated a singlefactor model of each orientation ${ }^{9}$ Reliability analysis revealed a maximum alpha of .84 with all nine items in the individualistic value-orientation scale and .90 with all ten items in the collectivistic value-orientation scale. Thus, each of the value orientations in the analysis that follows is a sum of $z$-score transformations of the corresponding items, with a mean of 0 and a 
standard deviation of 5.95 for the individualistic value-orientation and 7.19 for the collectivistic value-orientation.

\section{Independent and Interdependent Self-Construals}

One of the most successfully used measures of self-construal is the one developed by Gudykunst et al. (1996), designed to tap Markus and Kitayama’s (1991) conceptualization of independent or interdependent self-construals. All items on the independent self-construal scale clearly represent individuals who are unique and autonomous. All items on the interdependent self-construal scale, on the other hand, reflect those who are embedded in group relationships. For our measures of 'Independent Self-Construal' and 'Interdependent Self-Construal', respondents were asked to agree or disagree along a four-point scale with 14 items and 11 items, respectively, drawn from the measures by Gudykunst et al. (1996).$^{10}$ The response options were 'strongly disagree’ (coded 1), 'disagree’ (coded 2), 'agree’ (coded 3), and ‘strongly agree’ (coded 4). 'Independent Self- Construal' included items such as 'I try not to depend on others' and 'I take responsibility for my own actions'. Items for 'Interdependent Self-Construal' included items like 'I consult others before making important decisions' and 'I will stay in a group if it needs me, even if I am not happy with it’.

Again, we considered the possibility that the dimensionality of each of the two selfconstruals is not the same in the two countries. Preliminary analysis, however, suggests the covariance matrix proved to be similar. The eigenvalues from principal components analyses within each country strongly suggest one factor, with no obvious differences in patterns of factor loadings in the onefactor solutions. Cronbach's alpha for the linear composite of the 14 items for the independent self-construal is .80 in Japan and .78 in the United States. Somewhat different 
conclusions were reached with principal components analyses of the 11 items for the interdependent self-construal within nations. For both nations, the Scree Tests (Cattell, 1966) indicate a single factor, and no major differences in factor loadings are obvious between nations. But the following item has a poor factor discrimination: .371 among the Japanese and .252 among the Americans for 'My relationships with others are more important to me than my accomplishments'. Our attempts to improve the one-factor model by deleting specific items resulted in the elimination of this item. Alpha of the other ten items for the interdependent selfconstrual is .79 in Japan and .82 in the United States.

The results from the factor analysis of the combined American and Japanese samples are reported in Table 2. A principal components analysis of the combined American and Japanese samples yielded a single factor (see eigenvalues in Table 2). Cronbach's alpha for the linear composite of the 14 items is .83 for 'Independent Self-Construal' and maximum when all 14 items are included in the scale. Again, attempts to improve the one-factor model of the 'Interdependent Self-Construal' by deleting specific items resulted in the elimination of the same item. That item has a poor factor discrimination of .299. The eigenvalues and factor loadings are listed in Table 2. Reliability analysis reveals that Cronbach’s alpha of .836 is maximized with the other ten items in the scale. Thus, each of the self-construals in the analyses that follow is a sum of $z$-score transformations of the corresponding items, with a mean of 0 and a standard deviation of 7.89 for the independent self-construal and 6.35 for the interdependent self-construal.

\section{Culture}

Culture - that is, Japanese and American - is the key independent variable. Our hypotheses are that Japanese college students would score significantly lower on our measures of individualistic 
and collectivistic value orientations and independent and interdependent self-construals than Americans. In the analysis, culture is coded 1 for Japanese respondents and 0 for white Americans since all respondents with minority status are excluded from the analysis. The variable Japan has a mean of .54 with a standard deviation of .50 .

\section{Control Variables}

Gender. In the analysis, gender is coded 0 for females and 1 for males. For the combined sample, the variable Male had a mean of .58 with a standard deviation of .49 .

Age. Both samples had restricted age distributions because of the populations from which they were drawn. The mean age of the US sample was $19.62(\mathrm{SD}=1.55)$, with 91.8 percent between 18 and 21 years of age. The mean for the Japanese sample was 19.37 (SD = .64), with 99.1 percent between the ages of 18 and 21 . The two means were significantly different $(p<$ .001). The larger standard deviation for the American sample occurred because of six respondents who were older than traditional college students, with a maximum age of 34 years. The oldest respondent in the Japanese sample was 23. When the two samples were merged, the overall skewness of the distribution of age was 4.26. To reduce this skewness, age was truncated by converting the ages of the six older US students to 23.

Parents' Education. We wanted to include a measure of family socioeconomic status as a control variable. The questionnaire included measures of both family income and parents' education. As expected, a high percentage of American respondents (10.8 percent) did not provide an answer to the question about parents' income. The figure was even higher - 37.5 percent - for Japanese respondents. The greater non-response rate for Japanese probably can be attributed to their greater reluctance to provide such information and the greater likelihood of not 
knowing their parents' income. Consequently, parents' education, rather than income, is used as the indicator of family socio-economic status. Given the greater variety of family forms in Japan (see below), we chose to simply distinguish between respondents for whom at least one parent had a Bachelor's degree or higher and all other respondents. The variable Family Education, therefore, is a dichotomy coded 1 if at least one parent has a Bachelor's degree or above. In the Japanese sample, 66.5 percent of respondents have at least one parent with a Bachelor's degree, compared to 68.3 percent of the American respondents. For the combined sample, the variable Parents' Education (coded 1 if at least one parent has a Bachelor's degree or above) had a mean of .67 with a standard deviation of .47 .

Two Adult Home. Because of the possible effects on individualistic and collectivistic tendencies of being raised in a single-parent family, and because we expected such families to be less common in Japan, a measure of family structure was included in the analysis. In Japan, 7.6 percent of households with children have a single parent (Statistics Bureau, 2000), compared to 26.7 percent in the United States (US Census, 2001a). Developing a measure of family structure applicable to both cultures was confounded by the greater prevalence in Japan of certain types of families - especially three-generation and extended families (Sugimoto, 2003) - that are rarer in the United States. As a compromise based on these cultural differences, we classified respondents into two categories - those who were raised by one adult at any time in their lives, and those who were always raised by two or more adults. The exact question was phrased as follows: 'While growing up, how would you describe your household?' From the various response categories that were provided, 84.8 percent of the American sample and 95.4 percent of the Japanese sample were never in a single-adult household. The variable Two Adult Home (coded 1 for always with two or more adults) had a mean of .91 with a standard deviation of .29. 


\section{ANALYSIS}

\section{$t$-tests}

Table 3 reports simple comparisons, with no controls, of the Japanese and US samples for the value-orientation and self-construal measures. As expected, Japanese respondents score lower than Americans on both measures of individualistic and collectivistic value orientations, and the difference is significant beyond the .001 level. Likewise, our data reveal lower scores among Japanese than among Americans on our measures of independent and interdependent selfconstruals. Again, the differences are not only significant but also substantial $(p<.001)$.

\section{Regression Analysis}

Not evident yet, however, is whether the cultural differences observed in Table 3 sustain statistically with controls for the four socio-economic variables. This issue is addressed in the regression analysis in Table 4 where the two samples were merged $(N=802)$ with Japan as a dummy variable (coded 1 for Japanese and 0 for white Americans) and Male, Age, Parents’ Education, and Two Adult Home as the control variables.

Individualistic Values and Independent Self-Construal To examine whether Japanese college students are oriented less toward individualistic values than Americans, we regressed this scale on Japan and the four control variables. In Table 4 , the significant $(p<.001)$ inverse Beta of -.482 for Japan reflects the difference, with controls for the other variables, between Japanese and American respondents in their tendency to have an individualistic value-orientation. The negative sign indicates that Japanese, as predicted, are less oriented toward such values. A similar analysis is reported for independent self-construal. As before, when the control variables 
are included, the effect for Japanese is significant. The Beta indicating the direct effect for Japan is $-.486(p<.001)$, consistent with the predicted inverse relationship, is strong evidence that Japanese have a less independent self-construal than do Americans. Overall, therefore, Table 4 reveals a strong tendency for the Japanese respondents to be less individualistic than the Americans even with controls for gender, age, parents’ education, and family structures. For both measures of individualism, none of the control variables have significant direct effects.

\section{Collectivistic Values and Interdependent Self-Construal To assess whether Japanese} college students are less collectivistic than Americans, we then regressed the two scales of collectivism on the dummy variable for Japan and the four control variables. Table 4 shows, with the control variables, that Japanese scored significantly lower on collectivistic values than did Americans $($ Beta $=-.411, p<.001)$.

Similar findings are reported for interdependent self-construal. In Table 4, which contains the four control variables, the effect of being Japanese is substantial and significant beyond the .001 level. The direct effect (Beta) for Japan is -.436 in the predicted direction, indicating a strong tendency for the Japanese respondents to have a less interdependent self-construal. Table 4, therefore, provides rather strong support for our second hypothesis that Japanese college students, compared to Americans, are oriented less toward collectivism.

Again, none of the control variables have significant direct effects. These findings are intriguing given the work of Gilligan (1982), who indicates that sex is a powerful predictor of collectivistic and individualistic tendencies in a US sample. But when comparing both tendencies across cultures, our findings indicate that culture (Japanese versus Americans) has a larger effect than sex. In fact, it is the only significant predictor in the table. 
Additionally, we examined whether the two separate concepts of individualism and collectivism are inversely related among the Japanese, but positively related among the Americans. This possibility was considered by computing the partial correlations for each group of the respondents between the two individualism and collectivism variables, with controls for age, gender, parents’ education, and family structure. ${ }^{11}$ Contrary to Hofstede’s (1980) conceptualization, the partial correlation between ‘Individualistic Value-Orientation’ and 'Collectivistic Value- Orientation' is positive $(r=.395)$ and significant $(p<.001)$ in Japan. But the partial correlation between 'Independent Self-Construal' and 'Interdependent Self-Construal' is essentially zero $--.049(p=.156)$.

In the United States, the findings for the relationship between individualism and collectivism appear to be consistent with our expectation, but inconsistent with Hofstede’s conceptualization. The partial correlations of .539 between 'Individualistic Value-Orientation' and 'Collectivistic Value-Orientation’ and .165 between 'Independent Self-Construal' and 'Interdependent Self-Construal' are positive in the predicted direction, and both values are significant at the .001 level. The presence of strong positive correlations between individualism and collectivism is theoretically and methodologically important. Such correlations suggest that individualism and collectivism are not a bipolar continuum, but they co-vary positively. Those who are oriented more toward individualism tend to be also oriented more toward collectivism. And, for the American sample in the current study, this is consistently the case.

\section{DISCUSSION AND CONCLUSIONS}

The current research has been a challenge to a widespread assumption that Japanese are more collectivistic than are Americans - an assumption based primarily on a plethora of 
qualitative studies on stronger 'group-orientation' among Japanese compared to Americans and some empirical evidence on lower individualism in Japan compared to the United States. To challenge this assumption, we have conceptualized, in accord with Freeman (1997) and Kagitcibasi $(1987,1994)$, that individualism and collectivism are two different concepts rather than one with two extremes. Then, drawing on the previous cross-cultural research and theories, we have hypothesized that the Japanese college students tend less toward individualism and collectivism than do Americans. Our identical survey data collected at the same time and in very similar settings in Japan and the United States have contained Gudykunst et al.’s (1996) measures of individualistic and collectivistic value orientations and independent and interdependent self-construals which have been used successfully in comparative studies of Americans and Japanese.

Our assertions are modest and generalization must be approached with caution. First, our sample of the beginning college students has a restricted age distribution, though our respondents are part of what Japanese scholars call the 'global generation’ (Sugimoto, 2003). Second, our sample is over-representative of the highly educated. While all of them are enrolled in college, the sample is thus not fully representative even of this age group. Third, our analysis, because of the racial and ethnic homogeneity of Japanese society, is restricted to members of the dominant group in both counties (i.e. Japanese and Caucasians). Accordingly, the lack of variation on age, education, and ethnicity may have distorted the differences in the self-reported individualistic and collectivistic tendencies among college students in Japan and the United States.

Despite these shortcomings, evidence in the data supporting our hypotheses is rather convincing. As noted earlier, the direct effects (Beta) of Japan - with controls for sex, age, family type, and parents’ education - on both measures of individualism are inverse and 
significant $(p<.001)$ : -.482 for individualistic values and -.486 for independent self-construal. These findings support our prediction that Japanese college students tend less toward individualism than do Americans, and then suggest that the difference is apparent not only among adult samples (i.e. employees), as observed by Hofstede (1980), but also among a sample of young adults (i.e. college students) in the two counties. The findings for the cultural differences in collectivism are also consistent with our prediction. For both measures of collectivism, the Japanese sample has a significant $(p<.001)$ inverse effect of -.411 on collectivistic values and -.436 on interdependent self-construal. These findings, however, can be problematic since they are contradictory to the traditional stereotype that Japanese, compared to Americans, are more collectivistic.

In part, we argue, this could be because our measures of collectivism are not as specific as they might be preferred. Perhaps the Japanese respondents might emphasize different collectivistic factors, while they scored significantly lower on our general measures of collectivistic values and interdependent selfconstrual. For one thing, there are 'unique Japanese' values and 'unique US American’ values. It is worth noting, for example, that the concept of 'enryo' ('reserve' or 'restraint'), which is a response to a group pressure for conformity (Lebra, 1976), is not readily available in the United States because 'reserve' or 'restraint' does not fully capture the pragmatic meaning of 'enryo'. In the presence of this group pressure, Japanese are socialized to not only refrain from expressing their personal opinions that go against the majority, but also decline to state their desires, wishes, and preferences even when asked to state (Wierzbica, 1991). As the focus of I-C expands to emphasize cultural differences in this value dimension, the manner in which and the extent to which culturally unique values are apparent 
across cultures should, then, become a central concern, much as it has been in the qualitative study of $I-C$ across cultures.

Additionally, it is possible that the Japanese respondents might be more contextual than their American counterparts: the Japanese might be more collectivistic in one context but less collectivistic in another, while they may, in general, be less collectivistic than the Americans. When considering whether or not to cooperate with groups, Japanese people, for instance, might consider whether they would suffer socially-imposed punishment should they not cooperate. In fact, Yamagishi (1988a; see also Yamagishi, 1988b), in his study of a prisoner’s dilemma game, found that Japanese participants, in the absence of a sanctioning system, were less inclined to cooperate with the group than were Americans. But, when the opportunity for mutual sanctioning was available, the percent of Japanese who intend to cooperate increased substantially by about 30 percentage points (from 44.4 to 74.6 percent), whereas the comparable figure for the American participants was 19 percentage points (from 56.2 to 75.5 percent). In their study of hospital employees, Kobayashi et al. (2001; see also Kobayashi and Grasmick, 2002) also reported that Japanese are more likely to comply with group norms (i.e. workplace rules) because, compared to Americans, they perceive a greater threat of embarrassment (i.e. a loss of respect from significantothers). Thus, a better measure might involve items which specify the perceived probabilities that in-group members would detect uncooperative behavior and then the detection would lead to social sanctions. Perhaps a more refined measure of collectivism such as this, taking into account the risk of socially imposed punishment, might have produced results more consistent with the traditional stereotype.

While the measurement issue cannot be overlooked as an explanation for why the Japanese were significantly less collectivistic than the Americans in our data, there is another 
possibility. The past empirical evidence suggesting that Japanese are more collectivistic than Americans (e.g. Hofstede, 1980) tends to be studies of adult samples, while ours is a sample of college students. In fact, Kim et al. (1996), in their study of collectivism using a sample of college students, found that Japanese scored lower on collectivism than did Americans. In that study, as in ours, Japanese were also less oriented toward individualism. Some have argued that modern capitalism and participation in the global economy, over time, have made Japan and the Japanese younger generation less collectivistic and will continuously move them in this direction (see Bellah, 1985;Hayashi, 1992; Iwao, 1993). While this might be true and might be the longterm trend in Japan, another possibility, as we have argued, is while Japan is more willing to put its people under pressure to act harmoniously, the importance of collectivism is not as fully reinforced at home. For some adolescents, this combination of societal pressure and the lack of parental discipline for such a societal norm could be even the vehicle through which they later come to rebel against collectivism. Thus, we hope that future research of collectivism, as it applies to these two cultures, would involve examining whether a higher level of societal pressure of collectivity and conformative behavior in Japan and the lack of socialization for the culturally expected themes (i.e. collectivism) in the Japanese family are related to the lower collectivism among Japanese than among Americans. Then a rather convincing conclusion could be reached that these two factors intertwined with each other lead to the significant difference in a collectivistic value orientation and an interdependent self-construal between Japanese and American youths.

In conclusion, we want to emphasize again that our findings are only a preliminary examination of the differences in individualistic and collectivistic tendencies among college students in Japan and the US. First, our samples of college students are not representative of the 
general population in the two countries. Thus, our ability to generalize our findings is limited. Second, because of the racial and ethnic homogeneity of Japanese society, the analysis was restricted to members of the dominant group in both counties (i.e. Japanese and Caucasians). Third, our data do not include direct measures of societal pressure of collectivity and parental discipline. These measures, lacking in the current study, would strengthen the analyses. Fourth, we focused on Gudykunst et al.’s (1996) general scales of individualism and collectivism and their relationships to culture. However, future research needs to develop measures of culturally unique values and contextual values and incorporate them into research on differences in individualistic and collectivistic tendencies across cultures. Doing so, we hope, will then open the path for future exploration of a possibility that culture might be seen much more differentiated.

Finally and more importantly, we would encourage others not to lose sight of the importance of the distinction between individualism and collectivism. While the cultural variability of $I-C$ was conceptualized by Hofstede (1980; Hofstede and Hofstede, 2004) as a bipolar continuum, it is not reasonable to view that a culture and its people who are oriented more toward individualism than others are automatically oriented less toward collectivism. Thus, we would hope future comparative research to address the kinds of issues noted above and, then, increase our understanding of differences in individualistic and collectivistic tendencies across cultures.

\section{ACKNOWLEDGMENTS}

Research reported here was supported by the Grants-in-Aid for Scientific Research 
from the Japanese Ministry of Education, Culture, Sports, Science and Technology and

a grant from the College of Arts and Sciences, University of Oklahoma. Please direct

all correspondence to Emiko Kobayashi at the Foreign Language Institute, Kanazawa

University, Kakuma, Kanazawa, Ishikawa 920-1192, Japan. We wish to thank Professor

Harold G. Grasmick for his contributions to collecting the US data and his invaluable

inputs into earlier versions of the manuscript.

\section{NOTES}

1. College students, we argue, are a logical choice as a sample of respondents in testing whether individual-level behavior can be fully explained by the cultural-level scores regarding this dimension of cultural variability (i.e. individualism-collectivism). Current Japanese college students are part of what Japanese scholars call the 'global generation' (Sugimoto, 2003), to distinguish them from their predecessors - the wartime generation, postwar generation, and prosperity generation. They tend to be more pessimistic about the job market. At the same time, they were born in a period of declining birthrates and tend to have been raised with no or few siblings and unconditional love from their parents. Therefore, it is likely that they are less collectivistic than the generations of Japanese who preceded them.

2. College undergraduate students were chosen as respondents for two reasons. First, we had easier access to them in both countries than to younger adolescents or to adults. Second, the Japanese college undergraduate students, as noted above, are part of what Japanese scholars call the 'global generation' (Sugimoto, 2003). We realize, of course, that people who do not attend college are excluded from our research design and might be more (or less) individualistic and/or collectivistic than those who do attend college. But the inclusion of only college students was a constant across the two samples.

3. During the four months of preparing the first draft of the questionnaire, the Japanese Author discussed translation/cultural issues with four kinds of colleagues: those who were bilingual with Japanese as their native language, those who were bilingual with English as their native language, those who spoke only Japanese, and those who spoke only English. Although the draft of the questionnaire was not subjected to a formal 'back translation' (Matsumoto and Juang, 2004), in effect that process occurred for each questionnaire item as it was being developed in Japanese. The Japanese author then pre-tested the questionnaire in face-to-face interviews with a monolingual and a bilingual for whom Japanese was their native language, resulting in a few minor changes. Finally, the questionnaire was administered to a class of 30 Japanese college students as the last pre-test. No further changes resulted from this pre-test, suggesting that the Japanese author had successfully completed a version of 
the English questionnaire that would be meaningful to Japanese individuals like the ones eventually selected to be respondents in Japan.

4. The month of April was crucial to obtain students from both countries at approximately the same stages of their academic careers. While an academic year begins in late August or early September in universities in the US, the Japanese academic year begins in April. Thus, we chose to gather data in April 2003. We expected the vast majority of US students in the Introduction to Sociology class then would be nearing the end of their freshman or sophomore year. In fact, 50 percent of the US respondents were freshmen and another 30 percent were sophomores. In the Japanese university, we gathered data in courses at the onset of the sophomore year. Had we chosen freshman level courses in Japan, the students in the Japanese sample, unlike those in the US sample, would have had hardly any experience as college students at the time the data were collected. Indeed, 93 percent of the respondents in the Japanese sample were beginning sophomores.

5. Japanese students must declare a major before their admission to a university. In essence, there is no equivalent to an Introduction to Sociology (or any other subject) course taken by a large number of students outside their major.

6. Prior to the distribution of the questionnaire, students were informed that participation in the study was voluntary and both the anonymity of the respondent and the confidentiality of their responses were guaranteed. The questionnaires were then distributed to those who agreed to participate in the study.

7. We had to address the wide discrepancy between Japanese national and American state universities in racial and ethnic diversity, a discrepancy so wide that 'minority group' status could not be a variable in our analysis. Race/ethnicity is included, at least as a control, in tests of individualism-collectivism in the United States. We knew in advance, however, that this would be problematic in our research because of the racial and ethnic homogeneity of Japan. Whereas 75 percent of the US population is white (US Census, 2001b), typical estimates are that 95 to 98 percent in the Japanese population is racially and ethnically Japanese (Kerbo, 2000). According to a recent assessment (Sugimoto, 2003), only 5.4 million (slightly over 4 percent) of the 126.9 million residents of Japan are classified as members of 'minority groups'. Had we included a variable for race/ethnicity, separating minority group members from others, that variable would have been collinear with the dummy variable for Japan, possibly masking the effect of Japan, independent of its race/ethnic homogeneity. Consequently, our plan was to use only the questionnaires completed by Caucasian students in the US, excluding those who were self-identified minority group members. Likewise, we would omit from the analysis the few Japanese respondents who identified themselves as 'non-Japanese'.

8. The gender composition of universities in Japan and the US means that the proportion of males in the Japanese sample will be higher. In the American university only half (51 percent) of all students were male, a figure typical of state universities in 
the United States. In contrast, Japanese national universities are overwhelmingly male. According to figures from the Ministry of Education, Culture, Sports, Science and Technology (Statistics Bureau, 2003), 66 percent of all students enrolled in all national universities are males. In the particular Japanese university from which we gathered data, 71 percent of all students enrolled were males. Our two samples reflect these distributions.

9. Among the nine factors of individualistic values and the ten factors of collectivistic values necessary to perfectly reproduce the correlation matrix, 2 of each value orientation have eigenvalues greater than 1.0. According to the Kaiser Rule for determining the number of factors, a two-factor solution would be appropriate (Nunnally, 1967). Both an orthogonal and an oblique rotation of the two factors, in general, separate each of the two components as distinct factors. However, in a principal components analysis, the number of factors with eigenvalues greater than 1.0 is, in part, an increasing function of the number of items. With the larger number of items, the Kaiser Rule are more likely to overestimate the number of significant factors, and the Scree Discontinuity Test has been proposed as a preferable strategy for determining the number of factors (Nunnally, 1967). According to the logic of the Scree Test, the most obvious break in eigenvalues of individualistic and collectivistic values is the difference of 2.87 and 4.17, respectively, between the first and second factors, compared to .19 and .25 between the second and third, suggesting that a onefactor model would be appropriate for each value orientation. However, we would encourage others to replicate our measures and develop other items, examining their unidimensionality with various kinds of samples.

10. We excluded the following work-related items because of the nature of our sample (i.e. college students): 'I consult with co-workers on work-related matters' and 'I try to abide by customs and conventions at work'.

11. Additional analysis not reported here yielded similar findings. The correlations we found in oblique rotations between individualistic and collectivistic values were .310 in Japan and .437 in the US. The correlations between independent and interdependent self-construals were -.018 in Japan and .165 in the US.

\section{REFERENCES}

Abegglen, J.C. (1958) The Japanese Factory: Aspects of its Social Organization. Glencoe, IL: Free Press.

Azuma, H. (1986) 'Why Study Child Development in Japan?’, in H. Stevenson, H. Azuma and K. Hakuta (eds) Child Development and Education in Japan, pp. 3-12. New York: Freeman.

Bacon, W.F. and Ichikawa, V. (1988) 'Maternal Expectations, Classroom Experiences, and Achievement among Kindergartners in the United States and Japan', Human Development 31(6): 378-83.

Beccaria, C. (1963 [1764]) On Crimes and Punishment. Indianapolis, IN: Bobbs-Merrill. 
Bellah, R. (1985) Tokugawa Religion: The Cultural Roots of Modern Japan. New York: Free Press.

Bellah, R.N., Madsen, R., Sullivan, W.M., Swidler, A. and Tipton, S.M. (1985) Habits of the Heart: Individualism and Commitment in American Life. Berkeley: University of California Press.

Benedict, R. (1946) The Chrysanthemum and the Sword: Patterns of Japanese Culture.

Boston, MA: Houghton Mifflin.

Bentham, J. (1948 [1780]) The Principles of Morals and Legislation. New York: Hefner.

Cattell, R.B. (1966) 'The Scree Test for the Number of Factors', Multivariate Behavioral Research 1(2): 245-76.

Conroy, M., Hess, R.D., Azuma, H. and Kashiwagi, K. (1980) 'Maternal Strategies for Regulating Children’s Behavior: Japanese and American Families', Journal of CrossCultural Psychology 11(2): 153-72.

DeGooyer, M.J. (1992) 'A Comparison of Self-Concepts in Japan and the United States', in S. Iwawaki and K. Yoshihisa (eds) Innovations in Cross-Cultural Psychology, pp. 279-88. Lisse, Netherlands: Swets \& Zeitlinger.

Doi, T. (1971) The Anatomy of Dependence. New York: Kodansha International.

Doi, T. (1985) The Anatomy of Self. New York: Kodansha International.

Eisenstadt, S.N. (1996) Japanese Civilization: A Comparative View. Chicago, IL: University of Chicago Press.

Freeman, M.A. (1997) 'Demographic Correlates of Individualism and Collectivism: A Study of Social Values in Sri Lanka', Journal of Cross-Cultural Psychology 28(3): $321-41$.

Gilligan, C. (1982) In a Different Voice: Psychological Theory and Women's Development. Cambridge, MA: Harvard University Press.

Gudykunst, W.B., Matsumoto, Y., Ting-Toomey, S., Nishida, T., Kim, K. and Heyman, S. (1996) 'The Influence of Cultural Individualism-Collectivism, Self-Construals, and Individual Values on Communication Styles Across Cultures', Human Communication Research 22(4): 510-43.

Guisinger, S. and Blatt, S.J. (1994) 'Individuality and Relatedness: Evolution of a Fundamental Dialectic’, American Psychologist 49(2): 104-11.

Hampden-Turner, C. and Trompenaars, A. (1993) The Seven Cultures of Capitalism. New York: Doubleday.

Hayashi, C. (1992) 'Quantitative Social Research: Belief Systems, the Way of Thinking, and Sentiments of Five Nations', Behaviormetrika 19(2): 127-70.

Hoffman, D.M. (2003) 'Childhood Ideology in the United States', International Review Education 49(1-2): 191-211.

Hofstede, G. (1980) Culture's Consequences: International Differences in Work-Related Values. Beverly Hills, CA: SAGE.

Hofstede, G. and Bond, M.H. (1984) 'Hofstede’s Cultural Dimensions: An Independent Validating Using Rokeach’s Value Survey’, Journal of Cross-Cultural Psychology 15(4): 417-33.

Hofstede, G. and Hofstede, G.J. (2004) Cultures and Organizations: Software of the Mind. London: McGraw-Hill.

Iwao, S. (1993) The Japanese Woman: Traditional Image and Changing Reality. New York: Free Press. 
Jansen, M.B. (2000) The Making of Modern Japan. Cambridge, MA: Belknap/Harvard University Press.

Kagitçibasi, Ç. (1987) 'Individual and Group Loyalties: Are They Compatible?’ in Ç. Kagitçibasi (ed.) Growth and Progress in Cross-Cultural Psychology, pp. 94-104. Lisse, Netherland: Swets \& Zeitlinger.

Kagitçibasi, Ç. (1994) 'A Critical Appraisal of Individualism and Collectivism: Toward a New Formulation’, in U. Kim, H.C. Triandis, Ç. Kagitçibasi, S. Choi and G. Yoon (eds) Individualism and Collectivism: Theory, Method, and Applications, pp. 52-65. Thousand Oaks, CA: SAGE.

Kagitçibasi, Ç. (1996a) 'The Autonomous-Relational Self: A New Synthesis', European Psychologist 1(3): 180-6.

Kagitçibasi, Ç. (1996b) Family and Human Development across Cultures: A View from the Other Side. Mahwah, NJ: Lawrence Erlbaum.

Kawasaki, I. (1969) Japan Unmasked. Rutland, VT: C.E. Tuttle.

Keesing, R. (1974) 'Theories of Culture', Annual Review of Anthropology 3: 73-97.

Kerbo, H.R. (2000) Social Stratification and Inequality: Class Conflict in Historical, Comparative, and Global Perspective, 4th edn. New York: McGraw-Hill.

Kerbo, H.R. and McKinstry, J.H. (1998) Modern Japan: A Volume in the Comparative Societies Series. New York: McGraw-Hill.

Kim, M., Hunter, J.E., Miyahara, A., Horvath, A.M., Bresnahan, M. and Yoon, H.J. (1996) 'Individual versus Culture-Level Dimensions of Individualism and Collectivism: Effects on Preferred Conversation Styles', Communication Monographs 63: 29-49.

Kobayashi, E. and Grasmick, H.G. (2002) 'Workers’ Decisions to Comply: A Comparison of the Perceived Threats of Managerial Sanctions, Embarrassment, and Shame in Japan and the United States', NUCB Journal of Language, Culture and Communication 4: 1-12.

Kobayashi, E., Grasmick, H.G. and Friedrich, G.W. (2001) 'A Cross-Cultural Study of Shame, Embarrassment, and Management Sanctions as Deterrents to Noncompliance with Organizational Rules', Communication Research Reports 18(2): 105-17.

Lebra, T.S. (1976) Japanese Patterns of Behavior. Honolulu: University of Hawaii Press.

Lewis, C. (1995) Educating Hearts and Minds. Cambridge: Cambridge University Press.

Lincoln, J.R. and Kalleberg, A.L. (1985) 'Work Organization and Workforce Commitment: A Study of Plants and Employees in the US and Japan', American Sociological Review 50(6): 738-60.

Lincoln, J.R. and Kalleberg, A.L. (1990) Culture, Control, and Commitment: A Study of Work Organization and Work Attitudes in the U.S. and Japan. Cambridge: Cambridge University Press.

Lincoln, J.R., Kerbo, H.R. and Wittenhagen, E. (1995) 'Japanese Companies in Germany: A Case Study in Cross-Cultural Management', Journal of Industrial Relations 25: 123-39.

Lowell, P. (1888) The Soul of the Far East. Boston, MA: Houghton Mifflin.

Machida, S. (1996) 'Maternal and Cultural Socialization for Schooling: Lessons Learned and Prospects Ahead', in D.W. Shwalb and B.J. Shwalb (eds) Japanese Childrearing: Two Generations of Scholarship, pp. 241-59. New York: The Guilford Press.

Markus, H.R. and Kitayama, S. (1991) 'Culture and the Self: Implications for Cognition, 
Emotion, and Motivation', Psychological Review 98(2): 224-53.

Matsumoto, D. (2002) The New Japan: Debunking Seven Cultural Stereotypes. Boston, MA: Intercultural Press.

Matsumoto, D. and Juang, L. (2004) Cultural Psychology. Belmont, CA: Wadsworth.

Matsumoto, D., Weissman, M., Preston, K., Brown, B. and Kupperbusch, C. (1997)

'Context-Specific Measurement of Individualism-Collectivism on the Individual

Level: The IC Interpersonal Assessment Inventory (ICIAI)’, Journal of CrossCultural Psychology 28(6): 743-67.

McClain, J.L. (2002) Japan: A Modern History. New York: Norton.

Nakane, C. (1970) Japanese Society. Berkeley, CA: University of California Press.

Niedenthal, P. and Beike, D. (1997) 'Interrelated and Isolated Self-Concepts', Personality and Social Psychology Review 1(2): 106-28.

Nunnally, J.C. (1967) Psychometric Theory. New York: McGraw-Hill.

Olsen, M. (1978) The Process of Social Organization, 2nd edn. New York: Holt, Rinehart and Winston.

Parsons, T. (1951) The Social System. New York: Free Press.

Power, T.G., Kobayashi-Winata, H. and Kelly, M.L. (1992) 'Childrearing Patterns in Japan and the United States: A Cluster Analytic Study’, International Journal of Behavioral Development 15(2): 185-205.

Reischauer, E.O. (1970) Japan: The Story of a Nation. New York: Knopf.

Rohlen, T.P. (1983) Japan's High Schools. Berkeley: University of California Press.

Rokeach, M. (1973) The Nature of Human Values. New York: Free Press.

Rosenstone, R.A. (1988) Mirror in the Shrine: American Encounters with Meiji Japan. Cambridge, MA: Harvard University Press.

Schwartz, S.H. (1990) 'Individualism-Collectivism: Critique and Proposed Refinements', Journal of Cross-Cultural Psychology 21(2): 139-57.

Schwartz, S.H. (1992) 'Universals in the Content and Structure of Values' in M. Zanna (ed.) Advances in Experimental Social Psychology, Vol. 25, pp. 1-65. New York: Academic Press.

Schwartz, S. and Bilsky, W. (1987) 'Toward a Psychological Structure of Human Values', Journal of Personality and Social Psychology 53(3): 550-62.

Schwartz, S. and Bilsky, W. (1990) 'Toward a Theory of the Universal Content and Structure of Values', Journal of Personality and Social Psychology 58(5): 550-62.

Sengoku, T. (ed.) (2000) Chuugakusei, Koukousei no Nichijou Seikatsu ni kansuru Chousa: Nihon, Beikoku, Chuugoku no Sankakoku no Hikaku [A Survey on Daily

Lives: A Comparison of Middle and High School Students in Japan, the United States, and China]. Tokyo: Japan Youth Research Institute.

Sengoku, T. (ed.) (2006) Koukousei no Y jin Kankei to Seikatsu Ishiki: Nihon, Beikoku, Chuugoku, Kankoku no Yonkakoku no Hikaku [A Survey on Friendships and Attitudes toward Daily Lives: A Comparison of High School Students in Japan, the United States, China, and South Korea]. Tokyo: Japan Youth Research Institute.

Statistics Bureau (2000) The Japanese Bureau of Census, The Japanese Ministry of Public Management, Home Affairs, Posts and Telecommunications. Number of Households, available online at: [http://www.stat.go.jp/data/nihon/zuhyou/n0200900. xls], accessed 14 August 2004.

Statistics Bureau (2003) Number of Students at Japanese National Universities. Tokyo: 
The Ministry of Education, Culture, Sports, Science and Technology. Available online at: [http://www.mext.go.jp/b_menu/toukei/002/002b/koumoku.html], accessed 25 August 2006.

Sugimoto, Y. (2003) An Introduction to Japanese Society, 2nd edn. New York: Cambridge University Press.

Takano, Y. and Osaka, E. (1999) 'An Unsupported Common View: Comparing Japan and the U.S. on Individualism/Collectivism’, Asian Journal of Social Psychology 2: $311-41$.

Triandis, H.C. (1988) 'Collectivism vs. Individualism: A Reconceptualization of a Basic Concept in Cross-Cultural Psychology', in G. Verma and C. Bagley (eds) Cross-Cultural Studies of Personality, Attitudes and Cognition, pp. 60-95. London: Macmillan.

Triandis, H.C. (1990) 'Cross-Cultural Studies of Individualism-Collectivism', in J. Berman (ed.) Nebraska Symposium on Motivation 1989, Vol. 37, pp. 41-133. Lincoln: University of Nebraska Press.

Triandis, H.C. (1995) Individualism and Collectivism. Boulder, CO: Westview.

US Census (2001a) ‘Children’s Living Arrangements and Characteristics’, Current Population Reports, March, US Department of Commerce/US Census Bureau, Washington, DC.

US Census (2001b) 'Profiles of General Demographic Characteristics: 2000 Census of Population and Housing', US Department of Commerce/US Census Bureau, Washington, DC.

White, M. (1987) The Japanese Educational Challenge. New York: Free Press.

Wierzbica, A. (1991) 'Japanese Key Words and Cultural Values', Language in Society 20(3): 333-85.

Yamada, M. (2000) 'Yoriyoi Kosodate ni Oikomareru Hahaoyatachi [Mothers Driven into More Appropriate Child Rearing]', in Y. Meguro and S. Yazawa (eds) Shoushika Jidai no Jend to Hahaoya Ishiki [Gender and Motherhood in the Era of Declining Birth Rates], pp. 69-90. Tokyo: Shinyou-sha.

Yamagishi, T. (1988a) 'Exit from the Group as an Individualistic Solution to the Free Rider Problem in the United States and Japan', Journal of Experimental Social Psychology 24(6): 530-42.

Yamagishi, T. (1988b) 'The Provision of a Sanctioning System in the United States and Japan’, Social Psychology Quarterly 51(3): 265-71.

Emiko Kobayashi is an Associate Professor at the Foreign Language Institute of Kanazawa University in Japan. She received her $\mathrm{PhD}$ in communication from the University of Oklahoma. Her research interests include intercultural communication, crosscultural

psychology, and comparative sociology of deviant behavior, with a particular emphasis on comparisons between Japan and the United States. Address: Foreign

Language Institute, Kanazawa University, Kakuma, Kanazawa, Ishikawa 920-1192, Japan. [email: ekobayashi@ge.kanazawa-u.ac.jp]

Harold R. Kerbo has been a Professor of sociology at Cal Poly since 1977. He has been a Fulbright Professor in Japan, Thailand, and Austria, and a Visiting Professor in Great 
Britain, Germany, and Switzerland, Thailand and Japan. From June 2006 to August 2007, Professor Kerbo was the recipient of an Abe Fellowship to conduct field work on poverty and poverty programs in Thailand, Vietnam, Laos, and Cambodia. He is currently working on a book focused on Cambodia from this research. Professor Kerbo has published several books and numerous articles on the subjects of social stratification, comparative societies, corporate structure, and economic development and world poverty. He is the author of a basic sociology text book, Sociology: Social Structure and Social Conflict (Macmillan, 1989) and most importantly the author of the nations leading textbook on social stratification (Social Stratification and Inequality, published by McGraw-Hill, now in its seventh edition, recently translated into Spanish, and currently being translated into Russian). Along with John A. McKinstry, he is the author of Who Rules Japan? The Inner-Circles of Economic and Political Power (Greenwood/Praeger, 1995). Professor Kerbo is creator and general editor of the McGraw-Hill Comparative Societies Series which includes books on 11 countries. The first volume, Modern Japan (by Harold Kerbo and John McKinstry) was published in 1998. He has also coauthored the volumes, Modern Germany, with Professor Hermann Strasser at the University of Duisburg, Germany, and Modern Thailand, with Robert Slagter, both of which were published in 2000. Professor Kerbo is also the second author of the widely used text Social Problems now in its 10th edition (first author James Coleman, PrenticeHall, 2008). His latest book, World Poverty: Global Inequality and the Modern World System was published by McGraw-Hill in 2006. Address: Social Sciences Department, California Polytechnic State University, 1 Grand Avenue, San Luis Obispo, CA 93407, USA. [email: hkerbo@calpoly.edu]

Susan F. Sharp is the L. J. Semrod Professor of Sociology and Women's and Gender Studies at the University of Oklahoma. She obtained a PhD in Sociology from the University of Texas at Austin in 1996. Her research interests primarily focus on women and crime, women and the criminal justice system, and the effects of penal policies on the families of offenders. Professor Sharp is a former chair of the Division on Women and Crime of the American Society of Criminology. She is the founding editor of the division's official journal, Feminist Criminology. She is the editor of the text, The Incarcerated Woman: Rehabilitative Programming in Women's Prisons and has authored over 30 journal articles and book chapters as well as the book Hidden Victims: The Effects of the Death Penalty on Families of the Accused. Address: Department of Sociology, University of Oklahoma, 780 Van Vleet Oval KH 331, Norman, OK 73019, USA. [email: ssharp@ou.edu] 
Table 1 Descriptive statistics for independent and collectivistic value-orientation items $(N=802)$

\begin{tabular}{|c|c|c|c|c|}
\hline Item & Mean & SD & $\begin{array}{l}\text { Factor } \\
\text { loadings }^{a}\end{array}$ & $\begin{array}{l}\text { Factor } \\
\text { loadings }^{\mathrm{b}}\end{array}$ \\
\hline \multicolumn{5}{|l|}{ [ndividualistic value-orientation] } \\
\hline A sense of accomplishment & 6.182 & .886 & .648 & - \\
\hline Pleasure & 5.679 & 1.131 & .576 & - \\
\hline Ambitious & 5.173 & 1.444 & .727 & - \\
\hline Capable & 5.793 & 1.130 & .739 & - \\
\hline Imaginative & 5.805 & 1.183 & .544 & - \\
\hline Independence & 5.522 & 1.326 & .723 & - \\
\hline Intellectual & 5.865 & 1.063 & .682 & - \\
\hline Logical & 5.600 & 1.250 & .648 & - \\
\hline Self-respect & 5.770 & 1.286 & .657 & - \\
\hline \multicolumn{5}{|l|}{ [Collectivistic value-orientation] } \\
\hline Helpful & 5.992 & 1.099 & - & .688 \\
\hline Obedient & 4.970 & 1.609 & - & .765 \\
\hline Polite & 5.896 & 1.134 & - & .724 \\
\hline Obedience to parents & 4.743 & 1.772 & - & .725 \\
\hline Meet all obligations & 5.205 & 1.486 & - & .739 \\
\hline Harmony with others & 5.726 & 1.167 & - & .767 \\
\hline Being cooperative with others & 5.672 & 1.127 & - & .793 \\
\hline Sense of belonging & 5.014 & 1.518 & - & .697 \\
\hline Observing rites and social rituals & 4.684 & 1.468 & - & .757 \\
\hline Being interdependent with others & 4.901 & 1.318 & - & .534 \\
\hline
\end{tabular}

a Eigenvalues from principle component analysis: $3.96,1.09, .90, .71, .56, .51, .48, .44, .35$

b Eigenvalues from principle component analysis: $5.22,1.05, .80, .69, .52, .47, .41, .40, .26, .19$. 
Table 2 Descriptive statistics for independent and interdependent self-construal items and scales $(n=802)$

\begin{tabular}{|c|c|c|c|c|}
\hline Item & Mean & SD & $\begin{array}{l}\text { Factor } \\
\text { loadings }^{a}\end{array}$ & $\begin{array}{l}\text { Factor } \\
\text { loadings }^{\mathrm{b}}\end{array}$ \\
\hline \multicolumn{5}{|l|}{ Independent self-construal] } \\
\hline I should be judged on my own merit & 3.196 & .756 & .444 & - \\
\hline $\begin{array}{l}\text { Being able to take care of myself is a primary } \\
\text { concern for me }\end{array}$ & 3.460 & .627 & .490 & - \\
\hline My personal identity is very important to me & 3.451 & .653 & .623 & - \\
\hline I prefer to be self-reliant rather than dependent on others & 3.003 & .758 & .616 & - \\
\hline I am a unique person separate from others & 3.021 & .817 & .664 & - \\
\hline $\begin{array}{l}\text { If there is a conflict between my values and values of } \\
\text { groups of which I am a member, I follow my values }\end{array}$ & 3.010 & .779 & .597 & - \\
\hline I try not to depend on others & 2.878 & .777 & .620 & - \\
\hline I take responsibility for my own actions & 3.396 & .603 & .630 & - \\
\hline It is important for me to act as an independent person & 3.425 & .571 & .590 & - \\
\hline I should decide my future on my own & 3.464 & .640 & .462 & - \\
\hline What happens to me is my own doing & 3.115 & .756 & .561 & - \\
\hline I enjoy being unique and different from others & 3.189 & .759 & .665 & - \\
\hline $\begin{array}{l}\text { I am comfortable being singled out for praise and } \\
\text { rewards }\end{array}$ & 3.102 & .770 & .420 & - \\
\hline I do not support a group decision when it is wrong & 3.137 & .683 & .486 & - \\
\hline \multicolumn{5}{|l|}{ [Interdependent self-construal] } \\
\hline I consult with others before making important decisions & 2.970 & .775 & - & .576 \\
\hline I will sacrifice my self-interest for the benefit of my group & 2.732 & .753 & - & 609 \\
\hline I stick with my group with through difficulties & 2.914 & .803 & - & 678 \\
\hline I respect decisions made by my group & 3.075 & .643 & - & .701 \\
\hline $\begin{array}{l}\text { I will stay in a group if it needs me, even when I am not } \\
\text { happy with the group }\end{array}$ & 2.687 & .801 & - & .694 \\
\hline I maintain harmony in the groups of which I am a member & 3.189 & .635 & - & .625 \\
\hline $\begin{array}{l}\text { I respect the majority's wishes in groups of which I am a } \\
\text { member }\end{array}$ & 2.874 & .725 & - & .674 \\
\hline $\begin{array}{l}\text { I remain in groups of which I am a member if they need } \\
\text { me, even though I am dissatisfied with them }\end{array}$ & 2.618 & .750 & - & .636 \\
\hline $\begin{array}{l}\text { It is better to consult others and get their opinions } \\
\text { before doing anything }\end{array}$ & 2.890 & .684 & - & .608 \\
\hline $\begin{array}{l}\text { It is important to consult close friends and get their ideas } \\
\text { before making a decision }\end{array}$ & 3.011 & .684 & - & .543 \\
\hline
\end{tabular}

a Eigenvalues from principle component analysis: $4.52,1.48,1.17,1.03, .83, .79, .69, .61, .58, .55, .53, .45$ $.42,35$

${ }^{b}$ Eigenvalues from principle component analysis: 4.05, 1.54, $93, .78, .64, .53, .50, .45, .31, .29$. 
Table 3 One-tailed tests comparing Japanese and American samples

\begin{tabular}{llllll}
\hline & & & & \multicolumn{2}{c}{ Difference $^{\text {Japanese }}$} \\
\cline { 5 - 7 } Variable & \begin{tabular}{l} 
American \\
\cline { 5 - 7 }
\end{tabular} & $\mathbf{N = 4 3 3 )}$ & $\mathbf{N = 3 6 9 )}$ & $\boldsymbol{t}$ & $\boldsymbol{p}$ \\
\hline Individualistic value-orientation & -2.572 & 3.019 & -15.232 & $<.001$ \\
Independent self-construal & -3.583 & 4.204 & -16.114 & $<.001$ \\
Collectivisitic value-orientation & -2.840 & 3.333 & -13.472 & $<.001$ \\
Interdependent self-construal & -2.514 & 2.950 & -13.405 & $<.001$ \\
\hline
\end{tabular}

ane-tailed test for unequal variances. 
Table 4 Regression analysis of value orientations and self-construals, $n=802$ (one-tailed tests)

\begin{tabular}{|c|c|c|c|c|c|c|c|c|c|c|c|c|}
\hline & \multicolumn{3}{|c|}{$\begin{array}{l}\text { Individualistic } \\
\text { value-orientation }\end{array}$} & \multicolumn{3}{|c|}{$\begin{array}{l}\text { Independent } \\
\text { self-construal }\end{array}$} & \multicolumn{3}{|c|}{$\begin{array}{l}\text { Collectivistic } \\
\text { value-orientation }\end{array}$} & \multicolumn{3}{|c|}{$\begin{array}{l}\text { Interdependent } \\
\text { self-construal }\end{array}$} \\
\hline & Beta & b & $p$ & Beta & b & $p$ & Beta & b & $p$ & Beta & b & $p$ \\
\hline Japan & -.482 & -5.747 & $<.001$ & -.486 & -7.690 & $<.001$ & -.411 & -5.933 & $<.001$ & -.436 & -5.547 & $<.001$ \\
\hline Male & .051 & .615 & .061 & -.009 & -.142 & .392 & -.052 & -.765 & .060 & .013 & .161 & .355 \\
\hline Age & .021 & .134 & .252 & .040 & .331 & .103 & -.030 & -.230 & .177 & .011 & .073 & .369 \\
\hline Parents' education & -.014 & -.173 & .332 & -.043 & -.714 & .084 & .035 & .541 & .135 & .020 & .267 & .269 \\
\hline Two adult home & .002 & .034 & .479 & -.004 & -.116 & .496 & -.021 & -.527 & .257 & .024 & .523 & .232 \\
\hline (intercept) & .226 & & & -1.614 & & & 8.232 & & & .824 & & \\
\hline$R^{2}$ & .223 & & & 246 & & & .188 & & & .185 & & \\
\hline$p$ & $<.001$ & & & $<.001$ & & & $<.001$ & & & $<.001$ & & \\
\hline
\end{tabular}

